\title{
Década de 1980: as crises da economia e do Estado brasileiro, suas ambiguidades institucionais e os movimentos de desconfiguração do mundo do trabalho no país
}

Juliano Vargas ${ }^{1}$

Ednilson Silva Felipe ${ }^{2}$

Resumo: $\mathrm{O}$ artigo discute a configuração que o mercado nacional de trabalho (MNT) assumiu na economia nos anos oitenta, com ênfase para o fenômeno da informalidade. Primeiramente, é feita a apreciação do interregno 1930-1980 quanto às principais modificações econômicas e institucionais que se consubstanciaram na configuração do mercado de trabalho do despontar dos anos oitenta, mostrando o legado deixado ao país pela "era do desenvolvimentismo", uma sociedade urbano-industrial derivada de um descompasso entre um pujante crescimento econômico e um anêmico desenvolvimento social. Em seguida, expõe-se como na década de oitenta ocorreu a débâcle da economia brasileira e dela proveio uma crise do Estado, justificativa para o não compromisso formal por parte do governo com o pleno emprego, caracterizando uma contraposição aos princípios jurídicos vigentes. $\mathrm{Na}$ esteira destes acontecimentos iniciou-se a deterioração do mundo do trabalho, com maior insegurança laboral e, consequentemente, aumento da exposição dos cidadãos a atividades precárias e informais.

Palavras-chave: Instituições; Mercado Nacional de Trabalho; Economia Brasileira.

Classificação JEL: B52; J46; N36. 
Abstract: The paper discusses the configuration that national labour market took on the Brazilian economy in the eighties, with emphasis on informality phenomenon. Firstly, it is implemented an appreciation of the interregnum 1930-1980 concerning to the main economic and institutional changes which materialized in the labour market setting at the start of the eighties, showing the legacy left for the country by the "age of developmentalism", a urban-industrial society derived from a mismatch between a thriving economic growth and an anemic social development. Secondly, it exposes how in the eighties happened the débâcle of the Brazilian economy and from it came a State crisis, justification for the non-formal commitment by the government to full employment, featuring a contrast to the existing legal principles. In the path of these events began the deterioration of the national labour market, with greater job insecurity and, consequently, increased exposure of citizens to precarious and informal activities.

Keywords: Institutions; National Labour Market; Brazilian Economy.

JEL Classification: B52; J46; N36.

\section{Introdução}

A década de 1980 foi caracterizada por profundas transformações no cenário econômico internacional e nacional. As justaposições de elementos importantes de natureza conjuntural e estrutural obstaculizaram e até mesmo impediram a possibilidade da economia brasileira continuar funcionando nos moldes até então vigentes. As sucessivas crises econômicas e as mudanças institucionais promovidas visando superá-las também afetaram estruturalmente o mundo do trabalho, precipitando uma série de modificações nas relações trabalhistas e na conformação do MNT.

O presente artigo objetiva examinar a configuração que o MNT assumiu frente à economia brasileira na década de 1980, com ênfase para o fenômeno da informalidade. Propõe-se atingir esse intento em duas etapas. Primeiramente, constará uma apreciação do período compreendido entre 1930 e 1980 no que diz respeito às principais modificações institucionais que se consubstanciaram na configuração do MNT do despontar dos anos 1980. Em seguida, será analisado como as modificações econômicas e nas instituições que regiam o funcionamento do MNT à época impactaram o trabalho informal no país. Atenta-se para o fato de que as periodizações adotadas nesse estudo evi- 
dentemente comportam encadeamentos significativos entre si, devendo ser interpretadas apenas como referência que balizará a discussão.

Dentro desta perspectiva, pretende-se estabelecer nexos de convergência entre o objeto de estudo e os aspectos institucionais que o fundamentam. Este enfoque visa desenvolver uma análise do trabalho no Brasil, por levar em consideração os aspectos mais proeminentes da evolução da economia brasileira e, paralelamente, do processo contínuo de (re)configuração do MNT e das relações trabalhistas no país, além do que atesta que o referido processo permanece condicionando a questão da informalidade no Brasil.

\section{Antecedentes (1930-1980): breves considerações}

O período compreendido entre o início dos anos 1930 e fim dos anos 1980, conhecido na literatura econômica como a "era do desenvolvimentismo", foi marcado pelo crescimento, modernização e urbanização acelerada do país. Esse período foi caracterizado por substanciais transformações institucionais no âmbito econômico (impulso à industrialização sob a forma de uma reserva de mercado) e jurídico (que instituiu vínculos mais duradouros entre empregados e empregadores, especialmente os consubstanciados na Consolidação das Leis do Trabalho, em 1943). Além disso, houve significativa expansão do MNT, devido, sobretudo, à implantação gradual de alguns elos da indústria brasileira, iniciada ainda na década de 1930, sendo a ação estatal fortemente intervencionista durante todo o período. A política de intervenção estatal levou a modificação na estrutura econômica, deslocando seu "centro dinâmico" da economia baseada em atividades primárias para a indústria e para o mercado interno, resultando no fim do modelo agroexportador e no início do processo conhecido como de substituição de importações (Furtado, 2007).

Ajustaposição desses fenômenos ocasionou, inter alia, uma aguda concentração da população na zona urbana (tabela 1). Em 1940, mais de dois terços da população brasileira vivia nas zonas rurais e menos de um terço nas cidades; nos anos 1980 esse quadro se inverteu, passando para menos um terço da população morando no campo e mais de dois terços da população morando em áreas urbanas (Baltar, 2003; Barbosa, 2008).

\footnotetext{
1 De acordo com Fonseca, Cunha e Bichara (2013, p. 411), o conceito de desenvolvimentismo, como abstração, propõe-se captar "um padrão de comportamento detectável na condução da ação estatal tanto no sentido lato [...] como na formulação da política econômica em sentido mais restrito, o qual permite antever um projeto de longo prazo centrado na industrialização e na modernização do setor primário, implementado com auxílio de medidas governamentais voltadas a incentivar a substituição de importações e a diversificação da produção primária, com prioridade ao mercado interno”.
} 
TABELA 1 - POPULAÇÃO RESIDENTE TOTAL E TAXA DE URBANIZAÇÃO BRASIL (1940-1980)

\begin{tabular}{lcc}
\hline Ano & $\begin{array}{c}\text { População } \\
\text { (número de } \\
\text { habitantes) }\end{array}$ & $\begin{array}{c}\text { Taxa de urbanização } \\
(\%)\end{array}$ \\
\hline 1940 & 41.236 .315 & 31,24 \\
1950 & 51.944 .397 & 36,16 \\
1960 & 70.992 .343 & 44,67 \\
1970 & 94.508 .583 & 55,92 \\
1980 & 121.150 .573 & 67,59 \\
\hline
\end{tabular}

Fonte: IBGE/Pop, 2013; IBGE/CD, 2016. Elaboração própria.

Nota: até 1970 os dados foram extraídos do Anuário Estatístico do Brasil (IBGE, 2007).

A este repeito, Martine et al (1990, p.122) esclarecem que

nesse período correspondente a quarenta anos, o número de cidades de mais de quinhentos mil habitantes passou de três para catorze, [...] cidades de mais de quinhentos mil habitantes em 1940, reuniam um pouco mais de 10\% da população total do país, enquanto em 1980, concentrava $62 \%$ da população urbana, o que representava quase um terço da população total do país. Nesse período é importante considerar também o papel do Estado no contexto, como agente de investimento estatal, agente responsável pela modernização econômica. Cabe assim salientar que questões como emprego, desemprego e subemprego não eram de muita importância, o papel do Estado era dar condições para o país sair do subdesenvolvimento e se engajar no processo de crescimento econômico (grifos nossos).

Na construção dessa sociedade urbano-industrial, essas mudanças com vistas ao rápido crescimento econômico resultaram, também, na propagação de cinturões de pobreza nas grandes cidades, habitados por populações desfavorecidas, empenhadas em atividades precárias, principalmente atreladas à economia informal. Observa-se, conforme Theodoro (2005), que o crescimento da população urbana resultou de fluxos cada vez maiores de pessoas para os centros econômicos mais dinâmicos, o que provocou, sobretudo nas regiões com menor infraestrutura, a concentração da pobreza. A problemática 
urbana tornou-se cada vez mais manifesta, especialmente após 1950.

Nesse ínterim, aponta Dedecca (2005), ao fim do período de industrialização compreendido entre 1930 e 1980 cerca de metade da população ocupada não tinha acesso ao sistema de proteção social construído após 1940, especialmente no que diz respeito à instituição do salário mínimo e de toda uma legislação de regulação das leis do trabalho (mesmo essas medidas ainda não abarcando a totalidade da força de trabalho). Isso se traduziu na consolidação de um mercado de trabalho que funcionava em paralelo ao formalmente institucionalizado, caracterizado pela extensa presença de contratos trabalhistas informais, levando a um debate recorrente sobre a dicotômica divisão do MNT (formal e informal) nas décadas de 1960 e 1970, num forte descompasso entre um pujante crescimento econômico e um anêmico desenvolvimento social. Em linhas gerais, esse era o quadro existente no MNT no prenúncio dos anos 1980.

\section{A crise econômica brasileira nos anos oitenta}

Ao longo da década de 1980, o Brasil enfrentou sérias dificuldades devido à crise econômica iniciada ainda nos anos setenta (sobretudo devido aos efeitos dos choques do petróleo, em 1973 e 1979, e do aumento dos juros internacionais, entre 1978 e 1982) (ver Carneiro e Modiano, 2014). O crescimento via expansão do mercado interno abalizado em torno do setor industrial, que até então tinha sido viabilizado pelo aporte vultoso de recursos estrangeiros, foi atingido pela significativa deterioração dos termos de troca ocorrida entre 1980 e 1983, trazendo à tona a vulnerabilidade da economia brasileira aos condicionantes externos. Esse decênio foi marcado pelo baixo dinamismo da economia brasileira, que, após anos de robusto crescimento, observou essa taxa variar negativamente em 1981 (- 4,28\%) e depois novamente em 1983 $(-2,92 \%)$, denotando o esgotamento da acumulação de capital via substituição de importações (Coutinho, 1996).

A economia brasileira voltou a crescer em 1984 (5,4\%), apoiada pela recuperação econômica mundial e pela maturação do II Plano Nacional de Desenvolvimento (ver Fonseca e Monteiro, 2008). Todavia, mesmo com essa retomada, o PIB nos demais anos da década de 1980 apresentou uma média relativamente menor - inclusive com a reincidência de variação negativa no ano de 1988 (- 0,05\%) - do que as registradas no período compreendido entre o "milagre econômico" e o final da década de setenta (ver Lago, 2014). Em suma, o Brasil apresentou recessão entre 1981/83, recuperação/retomada do crescimento entre 1984/86 e estagnação entre 1987/89.

Soma-se a esse quadro o característico recrudescimento do processo inflacio- 
nário da economia brasileira na década de 1980. Fruto em grande medida da institucionalização de um sistema de indexação ${ }^{2}$ e da persistente estratégia monetária de emissão primária, a inflação era o grande problema a ser resolvido, cujos fracassos contribuíam para agravar ainda mais a conjuntura econômica adversa. Os sucessivos planos de estabilização - Cruzado (1986), Bresser (1987), Verão (1988) e Brasil Novo ou "Plano Collor" (1990) - propostos para tal fim não obtiveram sucesso, antes pelo contrário, pois a taxa de inflação que apresentou o índice de 110,2\% em 1980 chegou a 1782,9\% em 1989. A tabela 2 retrata o panorama econômico do Brasil na década de oitenta, no que diz respeito ao crescimento econômico e a inflação.

TABELA 2 - EVOLUÇÃO PERCENTUAL DAS TAXAS MÉDIAS ANUAIS DO PRODUTO INTERNO BRUTO (PIB) E DA INFLAÇÃO - BRASIL (1980-1989)

\begin{tabular}{lcc}
\hline Ano & PIB & Inflação (IPCA) \\
\hline 1980 & 9,2 & 110,2 \\
1981 & $-4,28$ & 95,2 \\
1982 & 0,81 & 99,7 \\
1983 & $-2,92$ & 211,0 \\
1984 & 5,39 & 223,8 \\
1985 & 7,91 & 235,1 \\
1986 & 7,50 & 65,0 \\
1987 & 3,61 & 415,8 \\
1988 & $-0,05$ & $1.037,6$ \\
1989 & 3,20 & $1.782,9$ \\
\hline Média & 2,35 & 462,9 \\
\hline
\end{tabular}

Fonte: IBGE/SCN, 2016; IBGE/SNIPC, 2016. Elaboração própria.

Para Salles (1997), a respeito da dinâmica inflacionária brasileira no período, tanto o método empregado para combatê-la quanto à postura teórica que permeou sua discussão à época explicam grandemente a não resolução desse problema ainda na década de oitenta. Isso por duas razões,

primeira, o sucesso de uma política de estabilização está diretamente ligado não à sua universalidade mas, ao contrário, a sua aderência à conjuntura e as peculiaridades institucionais que determinam o ritmo acelerado da elevação dos preços; segunda, os fundamentos da política de estabilização não devem provocar pressões adicionais sobre as instituições que foram criadas num 2 Referente à adoção da correção monetária, ainda na década de 1960. Os preços passavam a ser reajustados de acordo com uma regra oficial cujo percentual incorporava parte das perdas com a inflação passada. Ver Lopes (1985) e Sallum Jr. e Kugelmas (1991). 
regime de anormalidade inflacionária. Neste caso, uma política de choque e/ou congelamento, por violar esta norma, tende a representar a anti-regra de política econômica, devendo ser rejeitada por governos que pretendem ter a expectativa de sucesso a longo prazo (Salles, 1997, p. 141).

O autor corrobora a análise de que a causa mais importante da alta inflação verificada no período foi a indexação dos contratos, portanto. Acrescenta que a referida indexação tornou a inflação um "vício", permitindo que eles continuassem sendo celebrados e, simultaneamente, representou a "negação da estabilidade de preços", sendo um obstáculo à sua diminuição. Essa situação não era circunstancial, mas de fatores que estiveram na "raiz do funcionamento da economia" e foram a "resposta inata de um contexto" (Salles, 1997, p. 141-142). Nesse sentido, é possível dizer que a dinâmica da inflação crescente foi, inclusive, internalizada pelas próprias instituições, uma vez que o próprio funcionamento da economia e o que estabelecia as leis de indexação (institucionais, portanto) realimentavam o processo inflacionário.

A queda do ritmo de crescimento econômico e a aceleração da inflação constituíram-se nos sintomas aparentes do colapso do modelo econômico baseado na substituição de importações, como também de toda a institucionalidade que a cercava. Mais do que isso, as diversas implicações desta conjuntura no plano interno resultaram em uma grave crise fiscal do Estado brasileiro, secundadas por crises no balanço de pagamentos. A dívida externa foi largamente estatizada no período (socializando-se as perdas) e seus pesados encargos, somados à dívida interna, provocaram um profundo desequilíbrio estrutural no setor público e privado do país (tabela 3). A deterioração qualitativa da ação estatal ocorria simultaneamente à deterioração das contas públicas (Bresser-Pereira E Nakano, 1991; Bresser-Pereira, 1992). 
TABELA 3 - DÍVIDA LÍQUIDA DO SETOR PÚBLICO - \% PIB - BRASIL (1982-1989)

\begin{tabular}{cccc}
\hline Ano & Interna & Externa & Total \\
\hline 1982 & 16,7 & 20,0 & 36,7 \\
1983 & 14,4 & 25,8 & 40,2 \\
1984 & 15,9 & 23,6 & 39,5 \\
1985 & 16,4 & 23,3 & 39,7 \\
1986 & 17,5 & 24,6 & 42,1 \\
1987 & 16,5 & 26,6 & 43,1 \\
1988 & 18,8 & 22,5 & 41,3 \\
1989 & 25,2 & 21,5 & 46,7 \\
\hline
\end{tabular}

Fonte: Furuguem et al, 1996.

Para Cruz (1995, p. 121), a forma assumida pela crise nos anos oitenta esteve "indissoluvelmente ligada ao ciclo endividamento externo/estatização da dívida/transferência de recursos reais ao exterior e às relações entre os setores público e privado estabelecidas nas diversas fases desse ciclo" e, ainda, "a desestruturação fiscal e financeira do Estado é parte integrante das profundas modificações porque passa o capitalismo brasileiro a partir da crise do final dos anos setenta" (p. 142). E conclui, afirmando que "não se trata de opor o público ao privado, mas sim de apreender as formas de articulação público-privado" (p. 141). Sinteticamente, o cenário econômico nacional nessa década foi de uma economia brasileira que

esteve submetida a múltiplos problemas, a saber: instabilidade monetária, oscilação e estagnação do nível de atividade, constrangimentos decorrentes da necessidade de geração de elevados saldos na balança comercial e proteção contra a concorrência externa. Neste contexto, as empresas líderes adotaram procedimentos típicos de firmas oligopolistas, isto é, a ampliação da margem de lucro, a redução de custos e do nível de endividamento e a inovação tecnológica parcial e concentrada, o que significou, para a maior parte destas empresas, a postergação das decisões sobre novos investimentos (Mattoso e Pochmann, 1998, p. 234, grifos nossos).

Devido ao baixo nível de crescimento e a ameaça de hiperinflação, a crise fiscal do Estado e outros percalços, os anos oitenta receberam a alcunha de "década perdida”, apesar do reestabelecimento do regime democrático em 1985 e da 
promulgação de uma nova constituição em 1988. Configurou-se, assim, uma crise do padrão de financiamento baseado no Estado e no capital estrangeiro. Vale ressaltar que para um entendimento mais amplo dessas questões deve-se considerar a trajetória histórica do processo socioeconômico, que redesenhou um novo quadro nas relações sociais após a crise econômica mundial característica da década de 1970. Deve-se considerar também o processo interno de redemocratização política e as suas implicações socioeconômicas, verificadas no decorrer tanto da década de 1980, como nas décadas subsequentes (Bettiol, 2009).

\section{A crise do estado e as alterações institucionais nos anos oitenta}

Face ao panorama verificado na década de 1980 na esfera econômica, instalou-se uma crise no Estado brasileiro. Nesse sentido, é essencial destacar os elementos estruturais que impossibilitaram a economia brasileira e, consequentemente, o MNT, de prosseguir operando sob o arranjo institucional vigente. Desse modo, serão abordados os processos e as implicações das reformas implementadas no Brasil durante os anos oitenta, destacadas em duas áreas intimamente inter-relacionadas - identificadas como basilares para a dinâmica institucional - e que pautarão a análise posterior sobre a(s) reconfiguração(ões) que o MNT desvelou nesta e nas próximas décadas. São elas: o papel do Estado e a legislação trabalhista.

\subsection{Papel do Estado}

Mesmo na década de setenta, já se apontava a ineficiência do Estado como próprio da formação social brasileira ${ }^{3}$, incapaz de superar o "subdesenvolvimento, a desigualdade, a miséria de muitos e a injustiça social”, com o chamado "Estado-empresário" constituindo-se em um poderoso instrumento de um "tipo de desenvolvimento que mantém o subdesenvolvimento" (Bresser-Pereira, 1977, p. 24). Nos anos oitenta, a crise da economia brasileira degenerou na crise do Estado, manifestada a partir da sua incapacidade de intervir - decorrente também do avanço da globalização econômica e financeira - e da formatação da administração pública (Bresser-Pereira, 1992; Suzigan, 2004). A partir da segunda metade da década de 1980 , ampliou-se a crise econômica arrastando consigo boa parte das instituições que fundamentaram o desenvolvimento brasileiro até então. Em 1987 foram implementadas as 
primeiras medidas visando diminuir a margem de intervenção estatal, calcadas prioritariamente na abertura comercial (por meio de uma reforma aduaneira, preparando o terreno para reformas não tarifárias e, de certa forma, para as tarifárias que aconteceriam no início dos anos 1990). Note-se que a tendência do discurso era a modernização do Estado para adequação à economia internacional, seguindo-se daí uma abordagem quase que exclusivamente econômica das instituições (Ribeiro, 1997).

Em fins da década de 1980, outro importante elemento institucional ensejou o Estado brasileiro a promover ajustes. Emerso do plano internacional, o denominado de "Consenso de Washington" 4 influenciou sobremaneira a adoção de reformas estruturais orientadas ao acirramento do sistema de mercado, ao estabelecer uma série de medidas tidas como fundamentais para os países em desenvolvimento criarem um ambiente institucional favorável a um novo ciclo de crescimento autossustentável e liderado pelo setor privado (Yano e Monteiro, 2008). Os resultados daquele encontro foram sintetizados nas seguintes diretrizes:

i) disciplina da política fiscal, evitando grandes déficits fiscais frente às taxas de crescimento;

ii) redirecionamento dos gastos públicos, com restrição dos subsídios para áreas como a educação, saúde e infraestrutura;

iii) reforma tributária, ampliando a base sobre a qual incide a carga de tributos, com maior peso nos impostos indiretos e menor progressividade nos impostos diretos;

iv) taxa de juros determinadas pelo mercado e positivas (mas moderadas) em termos reais;

v) taxa de câmbio determinadas pelo mercado;

vi) liberalização do comércio exterior, liberando as importações, com ênfase para a eliminação das restrições quantitativas e redução de alíquotas;

vii) eliminação de restrições ao capital externo, permitindo investimento direto estrangeiro;

viii) privatização, com a venda de empresas estatais;

ix) desregulamentação, com redução da legislação de controle do processo econômico e das relações trabalhistas;

$\mathrm{x}$ ) segurança jurídica para os direitos de propriedade intelectual.

4 Termo que designa o resultado do encontro do Institute for International Economics em Washington D.C. (EUA), em 1989, entre representantes de países em desenvolvimento e de instituições oficiais, tais como FMI, Banco Mundial e o Departamento do Tesouro dos EUA. Ver Williamson (1989), Fiori (1995), Batista (1995) e Bresser-Pereira (1996). 
Para Batista (1995, p. 18),

as propostas do Consenso de Washington nas 10 áreas a que se dedicou convergem para dois objetivos básicos: por um lado, a drástica redução do Estado e a corrosão do conceito de Nação; por outro, o máximo de abertura à importação de bens e serviços e à entrada de capitais de risco. Tudo em nome de um grande princípio: o da soberania absoluta do mercado autorregulável nas relações econômicas tanto internas quanto externas.

Vê-se que a fragilidade do modelo de desenvolvimento por substituição de importações apresentou razões estruturais, cuja compreensão transcende uma análise puramente descritiva da economia brasileira. Deve-se ter em conta que as transformações desencadeadas no mundo a partir da década de 1970 inscreveram-se em uma lógica de dimensão mundial (Ribeiro, 1997). Esse processo e, particularmente, a crise institucional que o acompanhou (em particular a do Estado), explicam grandemente as mudanças do período (Suzigan, 2004).

\subsection{Legislação trabalhista}

Juridicamente, o marco nacional dos anos oitenta foi a promulgação da Constituição da República Federativa do Brasil de 1988 (CF/88), a “constituição cidadã", resultante das diversas organizações sociais derivadas do processo de abertura política (1979-1988) que se orientaram no sentido de pressionar pela participação na definição dos rumos do Brasil (Colnago, 2013). Esses movimentos da sociedade civil organizada foram essenciais na transição para a democracia que se institucionalizou com a $\mathrm{CF} / 88$, tida como a esperança da implantação do Estado de bem-estar social no Brasil (Ribeiro, 1997) ${ }^{5}$. Mérrien (1994) aponta que os fundamentos desse modelo se consubstanciam na proposta de um sistema de proteção social caracterizado por:

i) o Estado atuando como regulador, garantindo a segurança econômica;

ii) a redistribuição equitativa das riquezas produzidas como um fim;

5 O Estado de bem-estar social é um tipo de organização política e econômica que coloca o Estado como agente da promoção (protetor e defensor) social e organizador da economia. Nessa orientação, o Estado é o agente mediador da vida social, política e econômica do país em parceria com sindicatos e empresas privadas, em níveis diferentes, de acordo com cada país. Cabe a ele garantir serviços públicos e proteção à população. $\mathrm{O}$ "Estado de Bem-estar Social tem na sua origem três conceitos históricos distintos, que seriam o Estado-Providência francês, o Estado Social alemão e o Welfare State de origem anglo-saxã” (Magni e Calvete, 2005, p.2). 
iii) o Estado agindo como provedor de serviços;

iv) as políticas sociais devendo ter um papel relevante na correção das desigualdades.

No que se refere especificamente ao mundo do trabalho, Gonzalez et al (2009) destacam que embora as Constituições brasileiras desde 1934 incluíssem dispositivos com garantias mínimas para os trabalhadores, a CF/88 destacou-se pelo detalhamento, ao incluir 34 incisos no seu Art. $7^{\circ}$. Mas os avanços na regulação pública do trabalho não se restringiram à constitucionalização dos direitos que já estavam garantidos via legislação ordinária. Conforme Gonzalez et al (2009, p. 95-96), a CF/88 também

i) ampliou o prazo da licença-maternidade de 90 para 120 dias;

ii) instituiu a licença-paternidade;

iii) estipulou o acréscimo de um terço do salário normal à remuneração de férias;

iv) instituiu adicionais salariais, especialmente de penosidade;

v) garantiu o aviso prévio proporcional ao tempo de serviço, sendo no mínimo de 30 dias;

vi) ampliou a remuneração mínima das horas extras de $120 \%$ para $150 \%$ do salário normal;

vii) reduziu a jornada semanal máxima de 48 para 44 horas;

viii) aumentou a multa por dispensa sem justa causa de $10 \%$ para 40\% do montante devido do Fundo de Garantia por Tempo de Serviço (FGTS);

xix) garantiu a estabilidade no emprego da mulher gestante;

x) determinou a redução dos riscos inerentes ao trabalho, por meio de normas de saúde, higiene e segurança;

xi) garantiu a estabilidade do trabalhador eleito para a Comissão Interna de Prevenção de Acidentes, o que antes só era assegurado ao dirigente sindical.

Ainda de acordo com Gonzalez et al (2009 p. 96), tão importante quanto à constitucionalização e a extensão dos direitos dos trabalhadores foi "o fato de que estes constaram do capítulo referente a direitos e garantias fundamentais, e não do da ordem social e econômica, como nas Constituições anteriores". 
Este fato denota uma mudança de percepção a respeito da natureza das garantias trabalhistas, transitando de um "instrumento de enquadramento das relações de trabalho para um conjunto de direitos inalienáveis do trabalhador, independentemente da vontade do Estado ou do legislador”.

Assim, a CF/88 reforçou os princípios legais que asseguravam o monopólio da burocracia - no sentido weberiano, como um corpo (heterogêneo) de funcionários centralizados pela administração pública - na prestação de serviços e, além disso, agregou direitos trabalhistas à CLT. Todavia, a CF/88 contrastou sobremaneira com o cenário econômico então em curso, com que se verificou oposição entre seu projeto e o do Executivo. Senão, veja-se:

$\mathrm{Na} \mathrm{CF} / 88$, são basilares as seguintes características: consolidação do regime democrático; reconhecimento da dívida social; descentralização; redefinição do padrão regressivo de financiamento; elevação do salário real; crescimento econômico sustentado com mais emprego e ampliação dos impactos redistributivos. Os avanços na seguridade social, não obstante representarem mudanças estruturais sensíveis, sofrem já em 1989, efeitos da contra-reforma (sic), no momento mesmo da sua regulamentação (Romão, 2003, p.4, grifos nossos).

Nesse sentido, a CF/88 constituiu-se pelo tripé das políticas sociais de saúde, assistência social e previdência social (Sistema de Seguridade Social), tendo por objetivo garantir os direitos fundamentais dos cidadãos. Porém, em via contrária, o Estado apontou progressivamente para uma incompatibilidade entre suas receitas tributárias e as despesas decorrentes dos compromissos constitucionais impostos pelas políticas sociais. Além disso, como consequência dos preceitos do Consenso de Washington, o estado indicava perseguir caminho menos intervencionista. Tais elementos serviram como justificativa para emendas precoces na Carta Magna e gradativa elevação da carga tributária nos anos subsequentes.

\section{MNT nos anos oitenta: a informalidade histórica}

Internacionalmente, as transformações ocorridas no cenário econômico no período e as mudanças institucionais a ele vinculadas refletiram-se no mundo do trabalho. Com as políticas econômicas consideradas insuficientes para assegurar pleno emprego no país, a concorrência com o exterior se agudizou. 
Diante das tendências globalizantes, mecanismos tradicionais de regulação foram avaliados como ineficazes e a concorrência ganhou novos graus de liberdade.

Diante deste quadro, os novos investimentos tecnológicos, as reorientações produtivas e as mudanças organizacionais foram alternativas encontradas para tentar retomar o crescimento, e que, de certa forma, aconteciam no bojo do que alguns autores chamam de Terceira Revolução Industrial ${ }^{6}$, materializadas na reestruturação produtiva que acontecia inclusive em nível mundial. A queda da performance econômica precipitou a transição do "modelo" de produção fordista para o "modelo" de especialização flexível7, o que implicou em maior insegurança no mercado de trabalho (Mattoso, 1995). Nas palavras de Mattoso (1995, p. 78):

paralelamente à emergência de um novo padrão industrial [...] verificou-se novamente um processo no qual o novo padrão entra em choque com as próprias bases materiais que deram sustento à relação salarial e às demais formas constitutivas do mundo do trabalho anteriores, sem que nova articulação tenha sido criada. Este processo assumiria a forma de uma crescente ampliação da insegurança do trabalho que, por sua vez, apontaria para uma maior desestruturação do mundo do trabalho constituído no pós-guerra. Esta expansão da insegurança do trabalho se daria em diferentes níveis: insegurança no mercado de trabalho, insegurança no emprego, insegurança na renda, insegurança na contratação e insegurança na representação do trabalho (grifos nossos).

Por seu turno, Pochmann (1998a, p. 35-36) destaca algumas das mudanças no mundo do trabalho nesse período:

redução do emprego direto na produção e maior subcontratação de trabalhadores; alteração da organização da produção (just in time, lay out, logística, redução do tamanho da planta, terceirização e parcerias com fornecedores), que implica na redução do emprego no controle de qualidade, na manutenção, na administração e controle de estoques, entre outras; alteração da organização interna do trabalho: há redução de hierarquia

6 Caracterizada pela massificação das Tecnologias de informação e comunicação (TICs) no setor industrial. As TICs correspondem às tecnologias que interferem e mediam os processos informacionais e comunicativos dos seres e a principal responsável pelo crescimento e potencialização de sua utilização foi a popularização da internet. Ver Freeman e Perez (1988) e Dosi (1988).

7 "Nomina-se, genericamente, especialização flexível as novas formas de organização do processo de produção que surgiram em meados da década de 70 como alternativa ao "modelo" fordista de produção. Devido às diferenças, à contemporaneidade das experiências existentes e as controvérsias do seu real significado, as experiências mais consolidadas são nominadas de diversas formas, a saber: toyotismo, kalmarismo, pós-fordismo, neofordismo, especialização flexível, etc.” (CALVETE, 2006, p. 79). 
[desverticalização], trabalho em ilhas, trabalho mais qualificado nas atividades secundárias, que implica na redução do emprego nos segmentos administrativos e de supervisão e maior treinamento dos empregados, eventual estabilidade e alteração na jornada de trabalho, informatização do trabalho nos postos secundários e a redução do emprego regular nas atividades secundárias (segurança, alimentação, transporte, limpeza, entre outros) (grifos nossos).

Neste ínterim, surgiram novas formas de produção e de gestão de recursos humanos, voltadas ao redimensionamento dos empregos, intensificando as modificações no conteúdo, no significado, na natureza e nas relações trabalhistas. Essa desestruturação econômica repercutiu no mundo do trabalho através de sua crise estrutural. Tal crise, alimentada pela nova ordem econômica mundial ${ }^{8}$, levou à insegurança no mundo do trabalho, cujas variáveis mais danosas foram expansões do desemprego e da economia informal em escala global.

No caso específico do Brasil, como visto, os condicionantes externos e internos existentes na década de 1980 se sobrepuseram e desdobraram-se em uma crise do Estado, abalando a conformação socioeconômica construída gradativamente durante as décadas anteriores, quando norteadas por um maior grau de intervenção estatal voltada para a sociedade urbano-industrial. Assim, a crise do Estado brasileiro degenerou em uma crise de seu mundo do trabalho.

Apesar da queda da taxa de desemprego (tabela 4), o MNT foi substancialmente alterado. Neste período, o emprego assalariado com carteira cresceu em proporção menor que o sem carteira e a ocupação por conta própria. $\mathrm{O}$ quadro institucional suscitou aumento relativo da economia informal e queda do ritmo da expansão do emprego assalariado formal urbano, do crescimento de ocupações assalariadas sem registro formal e à progressiva intensificação da precarização do MNT. Esta queda no nível de emprego formal e no poder aquisitivo do assalariado resultou em retrocesso no padrão de vida de parcela significativa da população brasileira (Gomez, 2002).

8 Imposta por um conjunto de propostas elaboradas e expressas pela Assembleia Geral da ONU nos documentos "Declaração de Estabelecimento de uma Nova Ordem Econômica Mundial” (Resolução 3.201, de $1^{\circ}$ de maio de 1974), "Plano de Ação para o Estabelecimento de uma Nova Ordem Econômica Mundial" (Resolução 3.202, de $1^{\circ}$ de maio de 1974) e "Carta de Direitos e Deveres dos Estados” (Resolução 3.281, de 12 de dezembro de 1974). O objetivo alegado era diminuir a disparidade de poder nas relações econômicas entre países industrializados e países em desenvolvimento. Ver Singer (1978) e Rajagopal (2003). 


\begin{tabular}{l|c}
\hline Ano & Desemprego \\
\hline 1981 & 7,9 \\
1982 & 6,3 \\
1983 & 6,7 \\
1984 & 7,1 \\
1985 & 5,3 \\
1986 & 3,6 \\
1987 & 3,7 \\
1988 & 3,8 \\
1989 & 3,3 \\
\hline
\end{tabular}

Fonte: IBGE/PNAD, 2016. Elaboração própria.

Assim sendo, na década de oitenta as mudanças na economia brasileira alteraram internamente a dinâmica do MNT, embora com a manutenção do alto grau de informalidade historicamente observável (tabelas 5 e 6). Entretanto, nesse período o núcleo duro das estruturas industriais e produtivas foi pouco modificado, além do que o aumento do emprego no setor público corroborou para minimizar os impactos das transformações do mundo do trabalho.

TABELA 5 - DISTRIBUIÇÃO DA POPULAÇÃO OCUPADA POR POSIÇÃO NA OCUPAÇÃO (\%) - BRASIL (1981-1989)

\begin{tabular}{l|ccccccccc}
\hline $\begin{array}{l}\text { Posição na } \\
\text { ocupação }\end{array}$ & 1981 & 1982 & 1983 & 1984 & 1985 & 1986 & 1987 & 1988 & 1989 \\
\hline Empregador & 3,2 & 3,3 & 3,1 & 3,3 & 3,2 & 3,4 & 3,5 & 3,3 & 4,3 \\
$\begin{array}{l}\text { Empregados } \\
\quad \text { Com }\end{array}$ & 64,2 & 63,1 & 65,1 & 63,8 & 64,6 & 66,1 & 66,0 & 66,1 & 66,0 \\
$\begin{array}{l}\text { CTPS (1) } \\
\quad \text { Sem CTPS }\end{array}$ & 58,1 & 57,3 & 53,1 & 54,9 & 56,5 & 57,8 & 58,3 & 58,7 & 59,3 \\
$\quad$ A (2) & 41,9 & 42,7 & 46,9 & 45,1 & 43,5 & 42,2 & 41,7 & 41,3 & 40,7 \\
$\quad$ B (3) & 26,9 & 27,0 & 30,5 & 28,8 & 28,1 & 27,9 & 27,6 & 27,3 & 26,9 \\
$\begin{array}{l}\text { Conta } \\
\text { própria }\end{array}$ & 22,7 & 23,3 & 22,5 & 23,3 & 22,8 & 22,9 & 22,6 & 23,0 & 22,0 \\
$\begin{array}{l}\text { Não } \\
\text { remunerado }\end{array}$ & 9,9 & 10,3 & 9,3 & 9,6 & 9,4 & 7,6 & 7,9 & 7,6 & 7,9 \\
\hline Total & 100 & 100 & 100 & 100 & 100 & 100 & 100 & 100 & 100 \\
\hline
\end{tabular}

Fonte: dados brutos (IBGE/PNAD). Adaptado de Pereira (2003, p. 11).

Notas: (1) Participação dos trabalhadores com carteira assinada no total da categoria "empregados"; (2) Participação dos trabalhadores sem carteira assinada no total da categoria "empregados"; (3) Participação relativa dos trabalhadores sem carteira assinada no total do pessoal ocupado, índices estes necessários para a avaliação da magnitude da ocupação informal. 
VARGAS, J.; FELIPE, E. S. Década de 1980: as crises da economia e do Estado brasileiro, suas ambiguidades...

TABELA 6 - ESTRUTURA DAS OPORTUNIDADES OCUPACIONAIS NÃO AGRÍCOLAS (\%) - BRASIL (1989)

\begin{tabular}{l|c}
\hline Categorias ocupacionais & Pessoas ocupadas \\
\hline Assalariados de estabelecimentos & \\
Com mais de 1000 empregados & 16,3 \\
Com 10o a 10oo empregados & 13,5 \\
Com 10 a 100 empregados & 17,7 \\
Assalariados não formais & 27,0 \\
Trabalhadores por conta & 19,1 \\
própria & 2,1 \\
Trabalhadores sem & 4,3 \\
remuneração & 100,0 \\
$\quad$ Empregadores & \\
\hline Total da ocupação não agrícola & \\
\hline
\end{tabular}

Fonte: dados brutos (IBGE/PNAD, 1989; RAIS/MTb, 1989). In: MATTOSO e BALTAR, 1997).

Nota: dados absolutos da PNAD, corrigidos em função do crescimento da população entre os censos de 1980 e 1991.

Conforme Ulyssea (2005), mesmo no início dos anos oitenta o MNT se caracterizou por elevada proporção de trabalhadores sem contrato formal de trabalho. Embora esse número tenha sofrido pequena elevação nos três primeiros anos da década de 1980, o grau de informalidade permaneceu relativamente estável ao longo do decênio.

Além disso, salienta-se que duas dificuldades faziam-se sentir no MNT até o final dos anos oitenta. A primeira dizia respeito à existência dos problemas tradicionais de países em desenvolvimento, tais como: (i) taxas comprimidas de assalariamento; (ii) baixos salários; (iii) elevado subemprego; (iv) alta informalidade (Pochmann, 1998b).

Essa circunstância decorria do processo incompleto de estruturação do MNT, que, apesar de se desenvolver desde 1930, não chegou a se efetivar ainda em 1980. Em 1940, por exemplo, pouco mais de um terço da PEA ocupada era assalariada, e, em 1980, a taxa de assalariamento alcançava menos de dois terços da PEA ocupada. Pode-se observar, assim, que a acelerada expansão econômica do Brasil (taxas anuais médias de crescimento econômico de $7,0 \%$ ) era fator de robustecimento do assalariamento da força de trabalho, a despeito da expressiva expansão da PEA, que na década de 1970 teve aumento médio de 4,0\% ao ano (1,3 milhão de pessoas ingressavam anualmente no mercado de trabalho).

A segunda dificuldade que impactava o MNT até o final dos anos oitenta devia-se aos sinais de desemprego estrutural no Brasil, característico de economias industrializadas. Conforme o país aprofundava seu processo de consolidação 
de sociedade urbano-industrial, mantinha-se elevado excedente de mão de obra, não absorvido pelos movimentos de modernização das estruturas produtivas (Pochmann, 1998b).

Este desemprego estrutural gradativamente foi aumentado, sobretudo a partir de 1950, quando o país passou a incorporar mais aceleradamente a matriz produtiva já instalada nos países avançados. Com o relativo amadurecimento da industrialização nacional, na década de 1970, percebeu-se que subsistiram as discrepâncias socioeconômicas setoriais e regionais. Concomitantemente, $\mathrm{o}$ próprio MNT manteve-se bastante heterogêneo, com setores modernos e outros atrasados. A permanência dos setores atrasados no uso e na remuneração da força de trabalho desvelou, parcialmente, as características dessa evolução socioeconômica estruturalmente assimétrica no Brasil. Essa heterogeneidade estrutural refletia-se igualmente nas diversas maneiras de incorporar parcela significativa da sociedade brasileira nos frutos do crescimento econômico, já que apenas parte dela foi integrada aos segmentos organizados do MNT. A outra parte foi encaminhada para o setor informal, ou seja, alijados das proteções institucionais do mundo do trabalho, o que redundou em utilização precária e remuneração diferenciada setorial e regionalmente.

\section{Considerações finais}

Este artigo analisou como as transformações no cenário internacional e nacional resultaram na configuração que o mundo do trabalho assumiu no decorrer da década de 1980, com ênfase para o fenômeno da informalidade. Internamente, sucessivas crises econômicas e alterações institucionais promovidas visando superá-las afetaram estruturalmente as relações trabalhistas e a conformação do MNT.

De 1930 a 1980, interregno conhecido como a "era do desenvolvimentismo", o Brasil foi marcado pela evolução econômica e do MNT, com transformações institucionais que favoreceram vínculos mais duradouros entre empregados e empregadores. Nesse período, o país deixou de ser uma sociedade agrário-exportadora para tornar-se (majoritariamente) urbano-industrial, sob a atuação fortemente intervencionista do Estado. Todavia, a crescente concentração urbana da população resultou no aumento da pobreza e de atividades atreladas à economia informal, isto é, alheias às garantias sociais de proteção aos cidadãos. Com efeito, verificou-se forte descompasso entre um pujante crescimento econômico e um anêmico desenvolvimento social, cenário este legado aos anos oitenta.

Na década de 1980, o "modelo" de substituição de importações foi obstado 
devido à vulnerabilidade externa do Brasil e a queda do dinamismo econômico converteu-se em uma grave crise fiscal do Estado. Deste panorama irrompeu uma crise no Estado brasileiro, com que aumentaram as críticas ao seu papel e à legislação trabalhista, fomentadas pelo "Consenso de Washington". A $\mathrm{CF} / 88$ foi o marco das relações trabalhistas nessa década e a esperança da implantação do Estado de bem-estar social. Constitucionalizaram-se os direitos já garantidos via legislação ordinária e ampliaram-nos, formalizou-se o Sistema de Seguridade Social ao qual foi concedido o status de direitos e garantias fundamentais dos cidadãos, inalienáveis do trabalhador. Todavia, a $\mathrm{CF} / 88$ contrastou com o cenário econômico existente, opondo-se ao projeto do Executivo, o que serviu como justificativa para emendas constitucionais precoces. Essa conjuntura adversa degenerou em crise do mundo do trabalho e a reestruturação produtiva foi a opção escolhida para tentar retomar o crescimento.

A performance econômica precipitou o início da transição para a especialização flexível, com aumento da insegurança laboral mesmo no final dos anos oitenta. O quadro institucional suscitou o aumento relativo da economia informal, desvelando as características assimétricas da evolução socioeconômica no Brasil. Entretanto, nesse período o núcleo duro das estruturas industriais e produtivas foi sustentado e o aumento do emprego no setor público corroborou para minimizar os impactos dessas alterações.

Sumarizando, da débâcle da economia brasileira nos anos oitenta proveio uma crise do Estado, justificativa para o não compromisso formal por parte do governo com o pleno emprego, caracterizando uma contraposição aos princípios jurídicos vigentes. Na esteira destes acontecimentos iniciou-se a deterioração do mundo do trabalho e do MNT, com aumento da insegurança laboral e, consequentemente, acréscimos na histórica exposição dos cidadãos a atividades precárias e informais.

\section{Referências}

Baltar, P. A. Salários e preços: esboço de uma abordagem teórica. Campinas: Unicamp, 2003.

Barbosa, A. F. A formação do mercado de trabalho no Brasil. São Paulo: Alameda, 2008.

Batista, P. N. O consenso de Washington: a visão neoliberal dos problemas latino-americanos. In: Batista, P. N. et al. Em defesa do interesse nacional: desinfor-

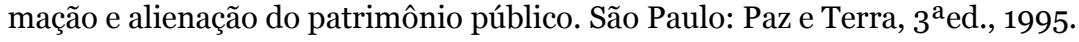

Bettiol, T. M. A informalidade do trabalho no Brasil dentro da perspectiva histórica. In: Congresso Internacional de História, 4., Maringá, p.779-791, 2009.

Brasil. Constituição [1988]. Constituição da República Federativa do Brasil (CF/88). São Paulo: Saraiva, 44aed., 2010. 
. Consolidação das leis do trabalho (CLT). Decreto-lei $\mathrm{n}^{0} 5.452$, de $1^{\mathrm{o}} \mathrm{de}$ maio de 1943. Coletânea de Legislação. São Paulo: Atlas, 104 a ed., 2000.

Bresser-Pereira, L. C. A crise do Estado: ensaios sobre a Economia Brasileira. São Paulo: Nobel, 1992. . Crise econômica e reforma do Estado no Brasil. São Paulo: 34, 1996. . Estado e subdesenvolvimento industrializado. São Paulo: Brasiliense, 1977.

Bresser-Pereira, L. C.; Nakano, Y. Resíduo inflacionário pós-congelamento e política monetária. In: FARO, C. (org.). A Economia Pós-Plano Collor II, Rio de Janeiro: Livros Técnicos e Científicos, p.149-157, 1991.

Calvete, C. S. Redução da jornada de trabalho: uma análise econômica para o Brasil. 232f. Tese (Doutorado em Economia Aplicada). Universidade Estadual de Campinas, Instituto de Economia, Campinas, 2006.

Carneiro, D. D.; Modiano, E. Ajuste Externo e Desequilíbrio Interno: 1980-1984. In: ABREU, Marcelo de Paiva (Org.). A ordem do progresso: dois séculos de política econômica no Brasil. Rio de Janeiro: Elsevier, ${ }^{\mathrm{a}}{ }^{\mathrm{ed}}$., p.263-280, 2014.

Colnago, C. S. A trajetória constitucional da redemocratização brasileira: evoluções e involuções de uma experiência democrática recente. Derecho y Cambio Social, v.33, p.1-19, 2013.

Coutinho, L. A fragilidade do Brasil em face da globalização. In: Baumann, R. (Org.). O Brasil e a economia global. Rio de Janeiro: Campus, p.219-237, 1996.

Cruz, P. R. Endividamento externo e transferência de recursos reais ao exterior: os setores público e privado na crise dos anos oitenta. Nova Economia, Belo Horizonte, v.5, n.1, ago.1995.

Dedecca, C. S. Notas sobre a evolução do mercado de trabalho no Brasil. Revista de Economia Política, v.25, n.1(97), p.94-111, jan./mar.2005.

Dosi, G. The nature of the innovative process. In: DOSI, G. et al (eds.). Technical change and Economic Theory. London: Frances Pinter Publishers, p.59o-6o7, 1988.

Faoro, R. [1957]. Os donos do poder: formação do patronato político brasileiro. São

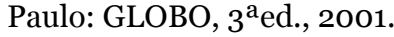

Fiori, J. L. Em busca do dissenso perdido: ensaios críticos sobre a festejada crise do Estado. Rio de Janeiro: Insight, 1995.

Fonseca. P. C. D.; Cunha, A. M.; Bichara, J. S. O Brasil na Era Lula: retorno ao desenvolvimentismo? Nova Economia, v.23, n.2, p.403-428, mai./ago.2013.

Fonseca, P. C. D.; Monteiro, S. M. M. O Estado e suas razões: II PND. Revista de Economia Política, v.28, p.3-20, 2008.

Freeman, C.; Perez, C. Structural crisis of adjustment, business cycles and investment behaviour. In: Dosi, G. et al (eds.) Technical Change and Economic Theory. London: Frances Pinter Publishers, p.38-66, 1988.

Furtado, C. [1958]. Formação econômica do Brasil. São Paulo: Companhia das Letras, 2007.

Furuguem, A. S.; Pessoa, L. P. P.; ABE, S. Dívida pública líquida: evolução 19821985 e perspectivas de curto prazo. Brazil Research, Banco de Investimento 
VARGAS, J.; FELIPE, E. S. Década de 1980: as crises da economia e do Estado brasileiro, suas ambiguidades...

Garantia S/A, 29/05/1996.

Gonzalez, R.; Galiza, M.; Amorim, B.; Vaz, F.; Parreiras, L. Regulação das relações de trabalho no Brasil: o marco constitucional e a dinâmica pós-constituinte. In: Políticas sociais: acompanhamento e análise - vinte anos da Constituição Federal. Brasília, IPEA, edição especial, n.17, v.2, 2009.

Gomez, M. T.S. As mudanças no mercado de trabalho e o desemprego em Presidente Prudente/SP - Brasil. Scripta Nova (Universidad de Barcelona). Barcelona: v.VI, n.119(32), ago.2002.

Instituto Brasileiro de Geografia e Estatística (IBGE). Anuário Estatístico do Brasil. Brasília: IBGE, 2007.

Instituto Brasileiro de Geografia e Estatística, Censo Demográfico (IBGE/CD). Taxa de Urbanização (1940-201O). Brasília: IBGE/CD, 2016. Disponível em: <http:// www.ibge.gov.br>. Acesso em: 10 jun.2016.

Instituto Brasileiro de Geografia e Estatística, Departamento de População e Indicadores Sociais (IBGE/Pop). População residente total (1872-2012). Brasília: IBGE/Pop, 2013. Disponível em: <http://www.ibge.gov.br>. Acesso em: 8 jun.2016.

Instituto Brasileiro de Geografia e Estatística, Pesquisa Nacional por Amostra de Domicílios (IBGE/PNAD). Taxa de Desemprego (TD). Brasília: IBGE/PNAD, 2016. Disponível em: <http://www.ibge.gov.br>. Acesso em: 7 jun.2016.

Instituto Brasileiro de Geografia e Estatística, Sistema de Contas Nacionais (IBGE/ $\mathrm{SCN}$ ). Produto Interno Bruto (PIB total: 1900-2013 e PIB per capita: 19002012). Brasília: IBGE/SCN, 2016. Disponível em: <http://www.ibge.gov.br>. Acesso em: 2 jun.2016.

Instituto Brasileiro de Geografia e Estatística, Sistema Nacional de Índices de Preços ao Consumidor (IBGE/SNIPC). Inflação: Índice Nacional de Preços ao Consumidor Amplo (IPCA: 1980-2013). Brasília: IBGE/SNIPC, 2016. Disponível em: $<$ http://www.ibge.gov.br>. Acesso em: 2 jun.2016.

Lago, L. C. A retomada do crescimento e as distorções do "milagre": 1967-1973. In: ABREU, Marcelo de Paiva (Org.). A ordem do progresso: dois séculos de política econômica no Brasil. Rio de Janeiro: Elsevier, $2^{\mathrm{a}}$ ed., p.213-240, 2014.

Lopes, F. Inflação Inercial, Hiperinflação e Desinflação: Notas e Conjecturas. Revista de Economia Política, v.5, n.2, 1985.

Magni, A. C.; Calvete, C. S. Estudo comparado dos Sistemas de Proteção Social: Alemanha e França. Leituras de Economia Política, Campinas, (11): p.1-26, dez.2005.

Martine, G.; Camarano, A. A.; Neupert, R.; Beltrão, K. Urbanização no Brasil: retrospectiva, componentes e perspectivas. In: Para a década de 90: prioridades e perspectivas de políticas públicas. Brasília, IPEA/IPLAN, v.3, p.99-159, 1990.

Mattoso, J. A Desordem do Trabalho. São Paulo: Scritta, 1995.

Mattoso, J; Baltar, P. E. A. Transformações estruturais e o emprego nos anos 90. Ensaios FEE, Porto Alegre, v.18, n.1, p.13-40, 1997.

Mattoso, J.; Pochmann, M. Mudanças estruturais e trabalho no Brasil. Economia e Sociedade, Campinas, (10): p.213-43, jun.1998. 
Mérrien, F. X. O Estado-Providência. Tradução de Sonia Tomazini. (Collection Que Sais - JE?), 1994.

Pereira. A. J. O comportamento da ocupação no Brasil: algumas evidências da informalização do formal. Revista Economia e Desenvolvimento, Santa Maria, n.15, p.1-15, 2004.

Pochmann, M. O trabalho sob fogo cruzado. São Paulo: Contexto, 1998a.

. Velhos e novos problemas do mercado de trabalho no Brasil. Indicadores Econômicos FEE, v.26, n.2, p.119-139, 1998b.

Rajagopal, B. International Law from below: development, social movements and Third World Resistance. Cambridge, 2003.

Ribeiro, S. M. R. Perspectivas da dinâmica institucional: a emergência do setor público não estatal. 143f. Dissertação (Mestrado em Sociologia). Universidade de Brasília, Departamento de Sociologia, Brasília, 1997.

Romão, F. L. Brasil década de 90: a recorrência das desigualdades em meio a muitas transformações. In: XI Congresso Brasileiro de sociologia, Campinas: sociologia e conhecimento além das fronteiras, v.1., p.251-252, 2003.

Salles, A. O. T. Alta inflação, hiperinflação e Política de Estabilização no Brasil: 1985/1990 - uma interpretação pós-keynesiana. 254f. Dissertação (Mestrado em Economia). Universidade Federal Fluminense, Faculdade de Economia, Niterói, 1997.

Sallum, Jr.; Kugelmas, E. O Leviathan declinante: a crise brasileira dos anos 80. Estudos avançados, 5(13), p.145-159, 1991.

Singer, H. W. The New International Economic Order: an overview. The Journal of Modern African Studies, v.16, n.4, p.539-548, 1978.

Suzigan, W. Crise e reconstrução do Estado. In: Em busca do novo: o Brasil e o desenvolvimento na obra de Bresser-Pereira. Nakano, Y.; Rego, J. M.; Furquim, L. (Orgs.). Rio de Janeiro: FGV, p.269-284, 2004.

Theodoro, M. L. As Características do mercado de trabalho e as origens do informal no Brasil. In: Ramalho, P. J.; Arrochellas, M. H. (Orgs.). Desenvolvimento, subsistência e trabalho informal no Brasil. São Paulo: Cortez, p.91-126, 2005.

Ulyssea, G. Informalidade no mercado de trabalho brasileiro: uma resenha da literatura. $R E P$, v.26, n.4(104), p.596-618, out./dez.2006.

Williamson, J. What Washington Means by Policy Reform. In: Williamson, John (ed.): Latin American Readjustment: How Much has Happened, Washington: Institute for International Economics, 1989.

Yano, N. M.; Monteiro, M. M. Mudanças institucionais na década de 1990 e seus efeitos sobre a produtividade total dos fatores. In: Anais do XXXVI Encontro Nacional De Economia, Salvador, dez.2008. 